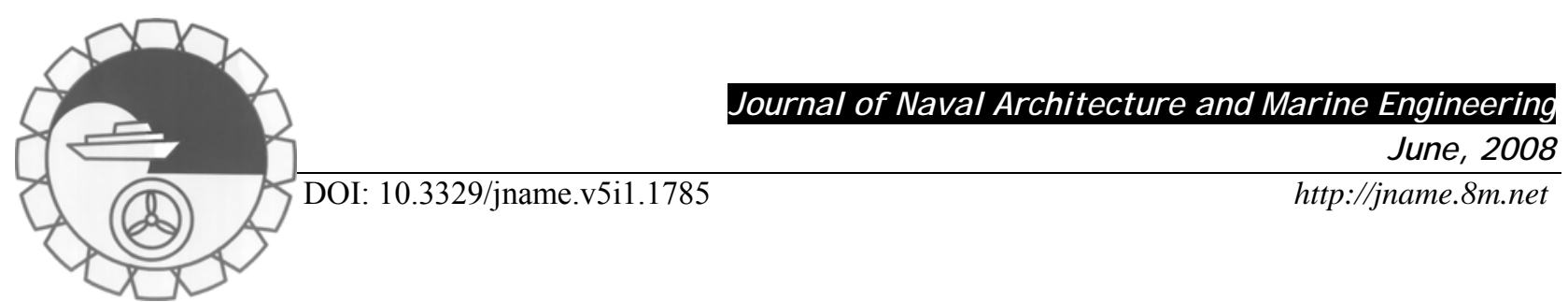

\title{
NUMERICAL SOLUTIONS OF HEAT AND MASS TRANSFER EFFECTS OF AN UNSTEADY MHD FREE CONVECTIVE FLOW PAST AN INFINITE VERTICAL PLATE WTH CONSTANT SUCTION
}

\section{V.Ambethkar}

Department of Mathematics, University of Delhi, Delhi, India. Email: vambethkar@maths.du.ac.in, Tel: 91-11-27666658.

\begin{abstract}
The objective of this work is to study heat and mass transfer in an unsteady MHD free convective flow past an infinite vertical plate with constant suction numerically. Dimensionless governing equations of the problem have been solved by using finite difference technique. Numerical solutions for temperature, velocity, concentration have been obtained for suitable parameters like Grashoff number, mass Grashoff number, Prandtl number and Schmidt number. Rate of heat transfer and mass transfer are studied. The results obtained are discussed with the help of graphs and tables to observe effect of various parameters concerned in the problem under investigation. Stability and convergence of the finite difference scheme is established.
\end{abstract}

Key words: MHD, unsteady, constant suction, finite difference technique, Heat and mass transfer.

\section{NOMENCLATURE}

\begin{tabular}{|c|c|c|c|}
\hline $\mathrm{C}_{\mathrm{p}}$ & concentration near plate & $\beta$ & volumetric coefficient of thermal expansion \\
\hline $\mathrm{B}_{0}$ & uniform magnetic field & $\sigma$ & the scalar electrical conductivity \\
\hline $\mathrm{C}_{\infty}$ & concentration of the ambient fluid & $\rho$ & density of the fluid \\
\hline$g$ & acceleration due to gravity & $v$ & reference kinematic viscosity \\
\hline$G_{r}$ & Grashof number & $\mu$ & Viscosity of the fluid \\
\hline$k$ & thermal conductivity of the fluid & $\omega$ & frequency of oscillation \\
\hline$N_{u}$ & Nusselt number & & \\
\hline $\mathrm{P}_{\mathrm{r}}$ & Prandtl number & $\mathrm{p}$ & wall conditions \\
\hline $\mathrm{S}_{\mathrm{c}}$ & Schmidt number & & Subscript \\
\hline $\mathrm{t}$ & dimensionless time & $\infty$ & ambient temperature \\
\hline$T$ & $\begin{array}{l}\text { temperature of the fluid in the } \\
\text { boundary layer }\end{array}$ & $\mathrm{p}$ & wall conditions \\
\hline$T_{\infty}$ & temperature of the ambient fluid & & Superscript \\
\hline$T_{p}$ & temperature at the plate & ' & differentiation with respect to $y$ \\
\hline$u, v$ & $\begin{array}{l}\text { The dimensionless } x \text { and } y \text { - } \\
\text { component of velocity. }\end{array}$ & & \\
\hline
\end{tabular}

\section{Introduction}

Combined heat and mass transfer problems are important in many processes and have therefore received a considerable amount of attention. In many mass transfer processes, heat transfer considerations arise due to chemical reaction and often due to the very nature of the process. In processes, such as drying, evaporation at the surface of a water body, energy transfer in a wet cooling tower and the flow in a desert cooler, heat and mass transfer occur simultaneously. Unsteady free convection flow past a vertical porous plate was investigated by 
Helmy (1998). Acharya et al. (2000) have studied free convection and mass transfer flow through a porous medium bounded by vertical infinite surface with constant suction and heat flux. But in those studies they considered the flow to be steady. Coming back to unsteady case, Kim (2000) investigated unsteady MHD convection heat transfer past a semi- infinite vertical porous moving plate with variable suction. Little extension to those problems has been done by Chamkha (2004). In this study author extended the problem for the case of mass transfer but restricted to the case of semi-infinite moving plate.

Unsteady oscillatory free convection flow plays an important role in chemical engineering, turbo machines, and aerospace technology. Such flows arise due to unusual motion of boundary or boundary temperature. Recently Singh et al. (2003) have investigated the effect of oscillatory suction velocity on free convection and mass transfer flow of a viscous fluid past an infinite vertical porous plate. Sahoo et al. (2003) have analyzed MHD unsteady free convective flow past an infinite vertical plate with constant suction and heat sink. Extension to this problem has been done by Muthucumaraswamy and Kumar (2004). In this study thermal radiation effect on moving infinite vertical plate in presence of variable temperature and mass diffusion is considered.

Because of the importance of suction in the fields of aerodynamics and space science our present study is motivated towards this direction. Our main purpose is to investigate numerically the problem of combined heat and mass transfer of an unsteady MHD flow past an infinite plate with suction. None of the above stated studies discusses completely about this. This is our motivation to the present study. The results of this study discussed for various numerical values of the parameters.
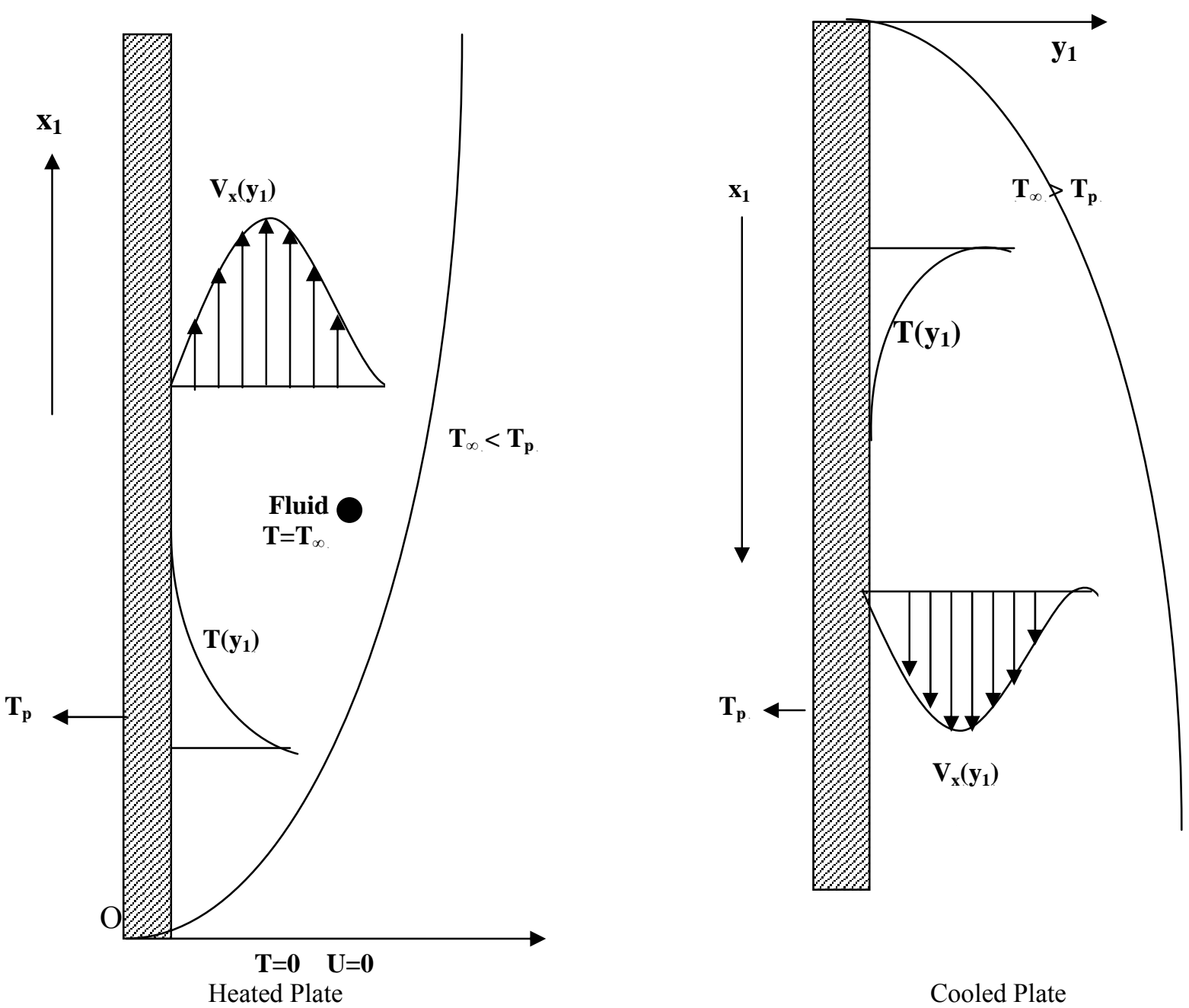

Fig. 1: Geometry of the problem 


\section{Mathematical Model}

Consider an unsteady two dimensional free convective flow of an electrically conducting viscous and incompressible fluid past an infinite, porous and vertical plate with constant suction. A magnetic field $\mathrm{B}_{0}$ is applied perpendicular to the plate. A system of rectangular coordinate axes ox $\mathrm{y}_{1} \mathrm{z}_{1}$ is taken such that $\mathrm{y}_{1}=0$ on the plate and $z_{1}$ is along its leading edge. All the fluid properties like density, velocity, pressure, temperature, concentration, and viscosity etc. are considered.

The influence of the density variation with temperature is considered only in the body force term. Its influence in other terms of the momentum and the energy equations is assumed to be negligible. The variation of expansion coefficient with temperature is considered to be negligible. This is the well-known Boussinesq approximation. Thus, under these assumptions, the physical variables are functions of $\mathrm{y}_{1}$ and $\mathrm{t}_{1}$ only and the problem is governed by the following system of equations

Continuity equation: $\frac{\partial v_{1}}{\partial y_{1}}=0$,

Momentum equations: $\frac{\partial u_{1}}{\partial t_{1}}+v_{1} \frac{\partial u_{1}}{\partial y_{1}}=g \beta\left(T_{1}-T_{\infty}\right)+\frac{v \partial^{2} u_{1}}{\partial y_{1}^{2}}-\frac{\sigma B_{0}^{2} u_{1}}{\rho}$,

Energy equation: $\frac{\partial T_{1}}{\partial t_{1}}+v_{1} \frac{\partial T_{1}}{\partial y_{1}}=\frac{k \partial^{2} T_{1}}{\partial y_{1}^{2}}$

Mass transfer equation: $\frac{\partial C_{1}}{\partial t_{1}}+v_{1} \frac{\partial C_{1}}{\partial y_{1}}=\frac{D^{\prime} \partial^{2} C_{1}}{\partial y_{1}^{2}}$

The initial and boundary conditions of the problem are

$$
\begin{aligned}
& \mathrm{t}_{1} \leq 0, \mathrm{u}_{1}\left(\mathrm{y}_{1}, \mathrm{t}_{1}\right)=0 \text {, } \\
& \mathrm{T}_{1}\left(\mathrm{y}_{1}, \mathrm{t}_{1}\right)=\mathrm{T}_{\infty} \text {. } \\
& \mathrm{C}_{1}\left(\mathrm{y}_{1}, \mathrm{t}_{1}\right)=\mathrm{C}_{\infty} \text {; } \\
& \mathrm{t}_{1}>0, \quad \mathrm{u}_{1}\left(0, \mathrm{t}_{1}\right)=\mathrm{V}_{\theta}, \\
& \mathrm{T}_{1}\left(0, \mathrm{t}_{1}\right)=\mathrm{T}_{\mathrm{P}}+\varepsilon\left(\mathrm{T}_{\mathrm{p}}-\mathrm{T}_{\infty}\right) \mathrm{e}^{\mathrm{i} \omega}{ }_{1} \mathrm{t}_{1} \text {, at } \mathrm{y}_{1}=0 \text {. } \\
& \mathrm{C}_{1}\left(0, \mathrm{t}_{1}\right)=\mathrm{C}_{\mathrm{P}}+\varepsilon\left(\mathrm{C}_{\mathrm{p}}-\mathrm{C}_{\infty}\right) \mathrm{e}^{\mathrm{i} \omega}{ }_{1} \mathrm{t}_{1} \text {. } \\
& t_{1}>0 \\
& \mathrm{u}_{1}\left(\infty, \mathrm{t}_{1}\right) \rightarrow 0 \text {, } \\
& \mathrm{T}_{1}\left(\infty, \mathrm{t}_{1}\right) \rightarrow \mathrm{T}_{\infty} \text {, } \\
& \mathrm{C}_{1}\left(\infty, \mathrm{t}_{1}\right) \rightarrow \mathrm{C}_{\infty}, \quad \text { as } \mathrm{y}_{1} \rightarrow \infty \text {. }
\end{aligned}
$$

Since the plate is assumed to be porous and through it suction with uniform velocity occurs, Equation (1) integrates to $v_{1}=-v_{0}$ is the constant suction velocity. Here, $u B_{1 \mathrm{~B}}$ is the velocity of the fluid, $\mathrm{TB}_{\mathrm{pB}}$ the temperature of the fluid near the plate, $\mathrm{TB}_{\infty \mathrm{B}}$ the temperature of the fluid far away from the plate, $\mathrm{C}_{\mathrm{p}}$ the concentration near the plate, $\mathrm{C}_{\infty}$ the concentration far away from the plate, $\mathrm{g}$ the acceleration due to gravity, $\beta$ the coefficient of volume expansion for heat transfer, $\beta^{\prime}$ the coefficient of volume expansion for concentration, $v$ the kinematic viscosity, $\sigma$ the scalar electrical conductivity, $\omega$ the frequency of oscillation, $\mathrm{BB}_{0 \mathrm{~B}}$ the applied uniform magnetic field, $\rho \mathrm{B}_{1 \mathrm{~B}}$ the density of the fluid, $\mathrm{k}$ the thermal conductivity and $\mathrm{tB}_{1 \mathrm{~B}}$ is the time.

From Equation (1) we observe that $v_{1}$ is independent of space co-ordinates and may be taken as constant. We define the following non-dimensional variables and parameters. 


$$
\begin{aligned}
& t=\frac{t_{1} V_{0}^{2}}{4 v}, y=\frac{V_{0} y_{1}}{4 v}, \\
& u=\frac{u_{1}}{V_{0}}, T=\frac{T_{1}-T_{\infty}}{T_{P}-T_{\infty}}, C=\frac{C_{1}-C_{\infty}}{C_{P}-C_{\infty}}, \\
& P_{r}=\frac{v}{k}, S_{c}=\frac{v}{D^{\prime}}, \\
& M=\frac{\sigma B_{0}^{2} v}{\rho V_{0}^{2}}, G_{r}=\frac{v g \beta\left(T_{P}-T_{\infty}\right)}{V_{0}^{3}} \\
& G_{m}=\frac{v g \beta^{\prime}\left(C_{P}-C_{\infty}\right)}{V_{0}^{3}}, \omega=\frac{4 v \omega_{1}}{V_{0}^{2}} .
\end{aligned}
$$

Now taking into account Equations (5), (6), (7) and (8), Equations (2), (3) and (4) reduce to the following nondimensional form

$$
\begin{aligned}
& \frac{\partial u}{\partial t}-4 \frac{\partial u}{\partial y}=4 \frac{\partial^{2} u}{\partial y^{2}}+4 G_{r} T-4 M u+4 G_{m} C \\
& \frac{\partial T}{\partial t}-4 \frac{\partial T}{\partial y}=\frac{4}{P_{r}} \frac{\partial^{2} T}{\partial y^{2}} \\
& \frac{\partial C}{\partial t}-4 \frac{\partial C}{\partial y}=\frac{4}{S_{c}} \frac{\partial^{2} T}{\partial y^{2}}
\end{aligned}
$$

With

$$
\begin{aligned}
& \mathrm{t} \leq 0, \\
& \mathrm{u}(\mathrm{y}, \mathrm{t})=0, \\
& \mathrm{~T}(\mathrm{y}, \mathrm{t})=0 ; \\
& \mathrm{t}>0, \\
& \mathrm{u}(0, \mathrm{t})=0, \\
& \mathrm{~T}(0, \mathrm{t})=1+\varepsilon e^{i \omega t}, \\
& \mathrm{C}(0, \mathrm{t})=1+\varepsilon e^{i \omega t} \cdot \mathrm{y}_{1} \rightarrow 0 \\
& \mathrm{t}>0, \\
& \mathrm{u}(\infty, \mathrm{t})=0, \\
& \mathrm{~T}(\infty, \mathrm{t})=0 \\
& \mathrm{C}(\infty, \mathrm{t})=0 . \text { as } \mathrm{y}_{1} \rightarrow \infty .
\end{aligned}
$$

The Grashof number $G_{r}>0$ represents external cooling of the plate and $G_{r}<0$ denotes external heating of the plate. $\mathrm{G}_{\mathrm{m}}$ the modified Grashof number, $\mathrm{S}_{\mathrm{c}}$ the Schmidt number, and $\mathrm{P}_{\mathrm{r}}$ the Prandtl number.

\section{Method of solution}

Here we sought a solution by finite difference technique of implicit type namely Crank- Nicolson implicit finite difference method which is always convergent and stable. This method has been used to solve Equations (9) (10) (11) subject to the conditions given by (12) (13) and (14). To obtain the difference equations, the region of the flow is divided into a gird or mesh of lines parallel to $y$ and $t$ axes. Solutions of difference equations are obtained at the intersection of these mesh lines called nodes. The values of the dependent variables $\mathrm{T}, \mathrm{u}$ and $\mathrm{C}$ at the nodal points along the plane $y=0$ are given by $T(0, t)$ and $u(0, t)$ and $C(0, t)$ hence are known from the boundary conditions. 
In the above Fig. 2, $\Delta y, \Delta t$ are constant mesh sizes along $\mathrm{y}$ and $\mathrm{t}$ directions respectively. We need a scheme to find single values at next time level in terms of known values at an earlier time level. A forward difference approximation for the first order partial derivatives of $\mathrm{u}, \mathrm{T}$ and $\mathrm{C}$ w.r.t. $\mathrm{t}$ and $\mathrm{y}$ and a central difference approximation for the second order partial derivative of $\mathrm{u}, \mathrm{T}$ and $\mathrm{C}$ w.r.t. $\mathrm{y}$ are used. On introducing finite difference approximations for:

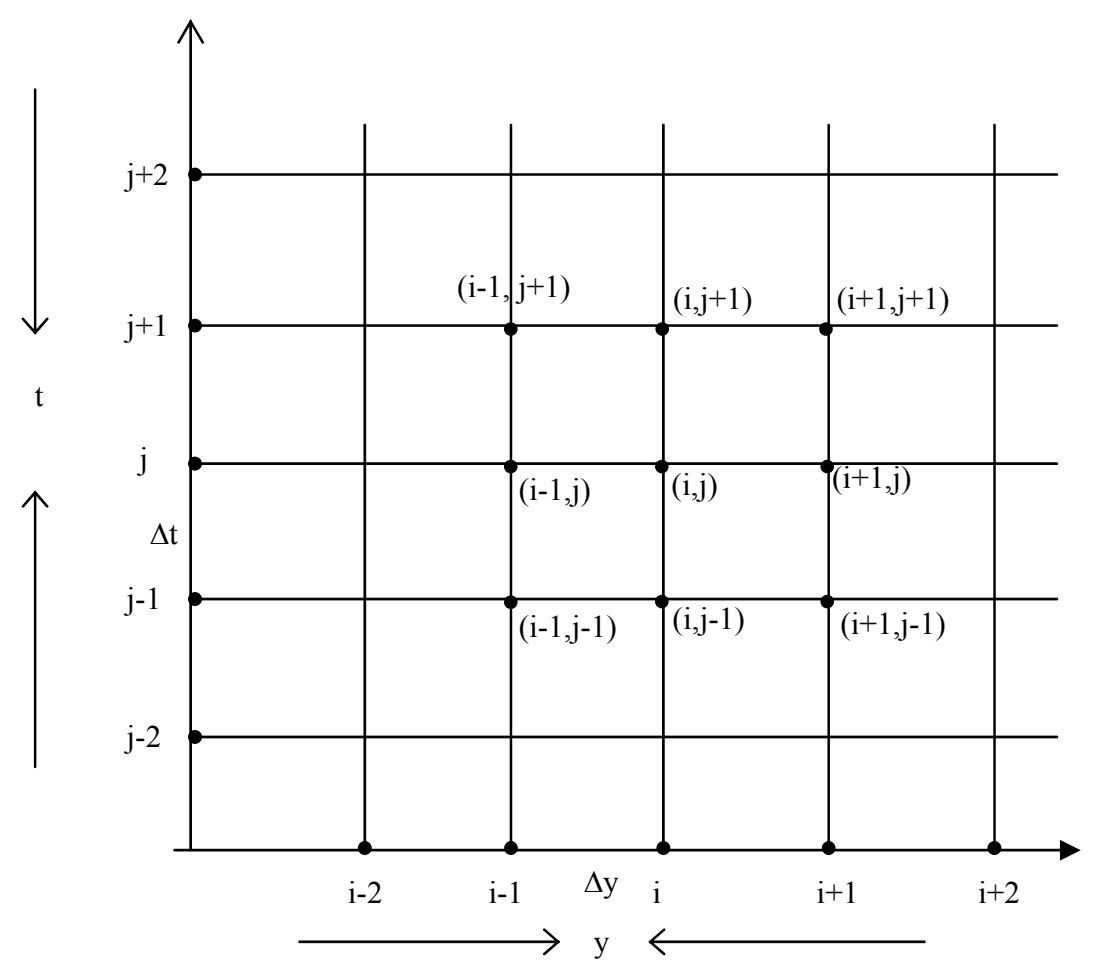

Fig. 2: Finite difference grid.

$$
\left.\begin{array}{l}
\left(\frac{\partial T}{\partial y}\right)_{i, j}=\frac{T_{i+1, j}-T_{i-1, j}+T_{i+1, j+1}-T_{i-1, j+1}}{4(\Delta y)}, \\
\left(\frac{\partial C}{\partial y}\right)_{i, j}=\frac{C_{i+1, j}-C_{i-1, j}+C_{i+1, j+1}-C_{i-1, j+1}}{4(\Delta y)}, \\
\left(\frac{\partial u}{\partial y}\right)_{i, j}=\frac{u_{i+1, j}-u_{i-1, j}+u_{i+1, j+1}-u_{i-1, j+1}}{4(\Delta y)}, \\
\left(\frac{\partial T}{\partial t}\right)_{i, j}=\frac{T_{i, j+1}-T_{i, j}}{\Delta t},\left(\frac{\partial C}{\partial t}\right)_{i, j}=\frac{C_{i, j+1}-C_{i, j}}{\Delta t},\left(\frac{\partial u}{\partial t}\right)_{i, j}=\frac{u_{i, j+1}-u_{i, j}}{\Delta t}, \\
\left(\frac{\partial^{2} T}{\partial y^{2}}\right)_{i, j}=\frac{T_{i+1, j}+T_{i-1, j}-2 T_{i, j}+T_{i+1, j+1}+T_{i-1, j+1}-2 T_{i, j+1}}{2(\Delta y)^{2}}, \\
\left(\frac{\partial^{2} C}{\partial y^{2}}\right)_{i, j}=\frac{C_{i+1, j}+C_{i-1, j}-2 C_{i, j}+C_{i+1, j+1}+C_{i-1, j+1}-2 C_{i, j+1},}{2(\Delta y)^{2}}, \\
\left(\frac{\partial^{2} u}{\partial y^{2}}\right)_{i, j}=\frac{u_{i+1, j}+u_{i-1, j}-2 u_{i, j}+u_{i+1, j+1}+u_{i-1, j+1}-2 u_{i, j+1}}{2(\Delta y)^{2}},
\end{array}\right\}
$$


The finite difference approximation of Equations (9), (10) and (11) are obtained with substituting Equation (15) into Equations (9), (10) and (11) then

$$
\begin{aligned}
& \left(\frac{u_{i, j+1}-u_{i, j}}{\Delta t}\right)-\left(\frac{u_{i+1, j}-u_{i-1, j}+u_{i+1, j+1}-u_{i-1, j+1}}{(\Delta y)}\right)=\left(\frac{u_{i+1, j}+u_{i-1, j}-2 u_{i, j}+u_{i+1, j+1}+u_{i-1, j+1}-2 u_{i, j+1}}{2(\Delta y)^{2}}\right) \\
& P_{r}\left(\frac{T_{i, j+1}-T_{i, j}}{\Delta t}\right)-P_{r}\left(\frac{T_{i+1, j}-T_{i-1, j}+T_{i+1, j+1}-T_{i-1, j+1} T_{i, j}+4 G_{m} C_{i, j}-4 M u_{i, j}}{(\Delta y)}\right)=2\left(\frac{T_{i+1, j}+T_{i-1, j}-2 T_{i, j}+T_{i+1, j+1}+T_{i-1, j+1}-2 T_{i, j+1}}{(\Delta y)^{2}}\right) \\
& S_{c}\left(\frac{C_{i, j+1}-C_{i, j}}{\Delta t}\right)-S_{c}\left(\frac{C_{i+1, j}-C_{i-1, j}+C_{i+1, j+1}-C_{i-1, j+1}}{(\Delta y)}\right)= \\
& 2\left(\frac{C_{i+1, j}+C_{i-1, j}-2 C_{i, j}+C_{i+1, j+1}+C_{i-1, j+1}-2 C_{i, j+1}}{(\Delta y)^{2}}\right)
\end{aligned}
$$

Multiplying both sides of Equations (16) (17) and (18) by $(\Delta t)$ and after simplifying, we obtain

$$
\begin{aligned}
& u_{i, j+1}+\frac{\Delta t}{(\Delta y)^{2}} u_{i, j+1}-\frac{\Delta t}{\Delta y}\left(u_{i+1, j+1}-u_{i-1, j+1}\right)-\frac{\Delta t}{2(\Delta y)^{2}} u_{i+1, j+1}-\frac{\Delta t}{2(\Delta y)^{2}} u_{i-1, j+1}=u_{i, j}+ \\
& \frac{\Delta t}{2(\Delta y)^{2}}\left(u_{i+1, j}+u_{i-1, j}-2 u_{i, j}\right)+\frac{\Delta t}{\Delta y}\left(u_{i+1, j}-u_{i-1, j}\right)+4 G_{r} \Delta t T_{i, j}+4 G_{m} \Delta t C_{i, j}-4 M \Delta t u_{i, j}
\end{aligned}
$$$$
T_{i, j+1}+\frac{4}{P_{r}} \frac{\Delta t}{(\Delta y)^{2}} T_{i, j+1}-\frac{\Delta t}{\Delta y}\left(T_{i+1, j+1}-T_{i-1, j+1}\right)-\frac{2 \Delta t}{P_{r}(\Delta y)^{2}}\left(T_{i+1, j+1}+T_{i-1, j+1}\right)=
$$

$$
\frac{2 \Delta t}{P_{r} \Delta y}\left(T_{i+1, j}+T_{i-1, j}-2 T_{i, j}\right)+T_{i, j}+\frac{\Delta t}{\Delta y}\left(T_{i+1, j}-T_{i-1, j}\right)
$$

$C_{i, j+1}+\frac{4}{S_{c}} \frac{\Delta t}{(\Delta y)^{2}} C_{i, j+1}-\frac{\Delta t}{\Delta y}\left(C_{i+1, j+1}-C_{i-1, j+1}\right)-\frac{2 \Delta t}{S_{c}(\Delta y)^{2}}\left(C_{i+1, j+1}+C_{i-1, j+1}\right)=$

$$
\frac{2 \Delta t}{S_{c} \Delta y}\left(C_{i+1, j}+C_{i-1, j}-2 C_{i, j}\right)+C_{i, j}+\frac{\Delta t}{\Delta y}\left(C_{i+1, j}-C_{i-1, j}\right)
$$

Now for Crank- Nicolson implicit method, let $\frac{\Delta t}{(\Delta y)^{2}}=r^{\prime}=1$ (method is always stable and convergent), under this condition the above equations can be written as

$$
\begin{aligned}
2 u_{i, j+1}- & \left(\frac{1}{2}+\frac{\Delta t}{\Delta y}\right) u_{i+1, j+1}+\left(\frac{\Delta t}{\Delta y}-\frac{1}{2}\right) u_{i-1, j+1}=\left(\frac{1}{2}+\frac{\Delta t}{\Delta y}\right) u_{i+1, j}+\left(\frac{1}{2}-\frac{\Delta t}{\Delta y}\right) u_{i-1, j}+ \\
& +4 G_{r} \Delta t T_{i, j}+4 G_{m} \Delta t C_{i, j}-4 M \Delta t u_{i, j}
\end{aligned}
$$




$$
\begin{aligned}
& \left(1+\frac{4}{P_{r}}\right) T_{i, j+1}+\left(\frac{\Delta t}{\Delta y}-\frac{2}{P_{r}}\right) T_{i-1, j+1}-\left(\frac{\Delta t}{\Delta y}+\frac{2}{P_{r}}\right) T_{i+1, j+1}=\left(\frac{\Delta t}{\Delta y}+\frac{2}{P_{r}}\right) T_{i+1, j}+\left(\frac{2}{P_{r}}-\frac{\Delta t}{\Delta y}\right) T_{i-1, j}+ \\
& \left(1-\frac{4}{P_{r}}\right) T_{i, j} \\
& \left(1+\frac{4}{S_{c}}\right) C_{i, j+1}+\left(\frac{\Delta t}{\Delta y}-\frac{2}{S_{c}}\right) C_{i-1, j+1}-\left(\frac{\Delta t}{\Delta y}+\frac{2}{S_{c}}\right) C_{i+1, j+1}=\left(\frac{2}{S_{c}}+\frac{\Delta t}{\Delta y}\right) C_{i+1, j}+\left(\frac{2}{S_{c}}-\frac{\Delta t}{\Delta y}\right) C_{i-1, j}+ \\
& \left(1-\frac{4}{S_{c}}\right) C_{i, j}
\end{aligned}
$$

\section{Numerical solutions and their accuracy}

To get the numerical solutions of the temperature $T$, velocity $u$ and concentration $C$, Necessary code is developed in code in Mathematica5.0. The logic of the program is divided into 4 modules as follows:

Module 1: Main, initially it creates three tables to hold the Numerical Solutions of Temperature, Velocity and concentration whose coefficients are allotted in the Module 2. After this, it calculates the numerical values at the next time step level. In order to do this, it uses another sub module named, Tridiagonal, which solves the tridiagonal matrix by using Gauss-Elimination method. Further it moves to the Module 3, for comparison of the numerical solutions with analytical solutions.

Module 2: Coeff Mat, we know that all the terms and their coefficients on RHS of Equations (22), (23) and (24) are known values from initial and boundary conditions. At every time step, for different values of ' $\mathrm{i}$ ', the finite difference approximation of Equation (24) gives a linear system of equations. Then, for $\mathrm{j}=0$ and $\mathrm{i}=1,2, \mathrm{n}-1$, Equation (24) gives a linear system of (n-1) equations for the (n-1) unknown values of ' $\mathrm{C}$ ' in the first time row in terms of known initial and boundary values. This module maintains coefficients of this linear system of equations. Similarly the above process repeats for the remaining Equations (23) and (22) to obtain the values of $\mathrm{u}$ and $\mathrm{T}$.

Module 3: Comparison, It compares the numerical solution with the analytical solution at every time step level. By making use of $\mathrm{T}$ and $\mathrm{C}$ into Equation (22), the numerical solutions for ' $\mathrm{u}$ ' are obtained.

To ensure the validity of our numerical solutions, we have compared this numerical solution for temperature, velocity and concentration for the case of suction for different Prandtl numbers with the available exact solutions in the literature. Table 1 and Table 2 show comparisons between the numerical values of temperature and velocity for $P_{\mathrm{r}}=6.75$ and 0.733 respectively obtained from the present study. It is clearly seen from these tables that results are in excellent agreement. The comparison tables Table 1 and Table 2 have been plotted and shown in Fig. 3 and Fig. 4. As the accuracy of the numerical solutions is very good, the curves corresponding to exact and numerical solutions are laying very close to the other. To ensure the efficiency of our code for velocity, we have given a table of numerical solution for velocity for water $\left(\mathrm{P}_{\mathrm{r} .}=6.75\right)$ for the cases of suction. These values have been plotted under Fig. 4.

\section{Results and Discussion}

For the purpose of discussing the results some numerical solutions are obtained for non-dimensional temperature $\mathrm{T}$, velocity u concentration $\mathrm{C}$. By using temperature the rate of heat transfer and by using concentration rate of mass transfer is obtained. The numerical solutions for the case of suction for temperature have been shown in Table 1. It can be seen from the table that the transient temperature decreases for the increase of $\mathrm{y}$. Similarly temperature field due to variation in $\mathrm{P}_{\mathrm{r}}$ for air, water, mercury etc has been found and observed that mercury has a stationary temperature. The numerical solutions for the case of suction for concentration have been shown in Table 5. It can be seen from the table that the transient concentration profiles decreases for the increase of $y$. The concentration profiles due to variation of $S_{c}$ for gases like hydrogen, oxygen and water vapor has been found but not giving here due to almost similar calculations. It can be found that hydrogen can be used for maintaining effective concentration field. The numerical solutions for the case of 
suction for velocity have been shown in Table 2. It can be seen from the table that the transient velocity profiles decrease for the increase of $y$. While finding velocity profiles numerical values for $G_{r}, G_{m}, M$ have been chosen suitably.

Table 1: Comparison of Temperature profiles for $\mathrm{P}_{\mathrm{r}}=6.75, \mathrm{t}=0.1$ for the case of suction

\begin{tabular}{|r|r|r|}
\hline \multicolumn{1}{|c|}{$\mathbf{y}$} & \multicolumn{1}{|c|}{$\begin{array}{c}\text { Analytical } \\
\text { Solution }\end{array}$} & \multicolumn{1}{c|}{$\begin{array}{c}\text { Numerical } \\
\text { Solution }\end{array}$} \\
\hline 0 & 1 & 0.409811 \\
\hline 0.05 & 0.408622 & 0.167945 \\
\hline 0.1 & 0.168723 & 0.068825 \\
\hline 0.15 & 0.689642 & 0.028205 \\
\hline 0.2 & 0.021486 & 0.011558 \\
\hline 0.25 & 0.011598 & 0.004736 \\
\hline 0.3 & 0.004986 & 0.001940 \\
\hline 0.35 & 0.001875 & 0.000793 \\
\hline 0.4 & 0.000985 & 0.000321 \\
\hline 0.45 & 0.000456 & 0.000030 \\
\hline 0.5 & 0.000369 & 0.000032 \\
\hline 0.55 & 0.000892 & 0.000021 \\
\hline 0.6 & 0.000098 & 0.000011 \\
\hline 0.65 & 0.000069 & 0.000001 \\
\hline 0.7 & 0.000086 & $0.1 \mathrm{E}-07$ \\
\hline 0.75 & 0.0000045 & 0.00000001 \\
\hline 0.8 & 0.0000001 & $0.1 \mathrm{E}-08$ \\
\hline 0.85 & $0.1 \mathrm{E}-05$ & $0.1 \mathrm{E}-09$ \\
\hline 0.9 & $0.1 \mathrm{E}-06$ & $0.1 \mathrm{E}-11$ \\
\hline 0.95 & $0.1 \mathrm{E}-06$ & \\
\hline 1 & & \\
\hline & & \\
\hline 0 & & \\
\hline 0.96 & & \\
\hline
\end{tabular}

Table 2: Comparison of velocity for $\operatorname{Pr}=0.733, M=2, G_{r}=4, G_{m}=2, T=0.0975$

\begin{tabular}{|c|c|c|}
\hline $\mathbf{y}$ & $\begin{array}{c}\text { Analytical } \\
\text { Solution }\end{array}$ & $\begin{array}{c}\text { Numerical } \\
\text { Solution }\end{array}$ \\
\hline 0 & 1 & 1 \\
\hline 0.05 & 0.952677 & 0.909804 \\
\hline 0.1 & 0.896203 & 0.820757 \\
\hline 0.15 & 0.832823 & 0.733967 \\
\hline 0.2 & 0.764716 & 0.650451 \\
\hline 0.25 & 0.693946 & 0.571107 \\
\hline 0.3 & 0.62241 & 0.49668 \\
\hline 0.35 & 0.551797 & 0.427745 \\
\hline 0.4 & 0.483555 & 0.364691 \\
\hline 0.45 & 0.418869 & 0.307724 \\
\hline 0.5 & 0.358648 & 0.256872 \\
\hline 0.55 & 0.303532 & 0.211999 \\
\hline 0.6 & 0.253906 & 0.172823 \\
\hline 0.65 & 0.20992 & 0.138938 \\
\hline 0.7 & 0.171526 & 0.109839 \\
\hline 0.75 & 0.138509 & 0.084943 \\
\hline 0.8 & 0.11053 & 0.063609 \\
\hline 0.85 & 0.08716 & 0.04516 \\
\hline 0.9 & 0.067916 & 0.02889 \\
\hline 0.95 & 0.05229 & 0.014079 \\
\hline 1 & 0.039778 & 0 \\
\hline
\end{tabular}


Table 3: Numerical values of rate of heat transfer

\begin{tabular}{|c|c|}
\hline $\mathrm{t}$ & $\begin{array}{c}\text { Numerical values } \\
\text { of } N_{u}\end{array}$ \\
\hline 0.0025 & 18.69578 \\
\hline 0.005 & 16.4067 \\
\hline 0.0075 & 14.66101 \\
\hline 0.01 & 13.29947 \\
\hline 0.0125 & 12.21477 \\
\hline 0.015 & 11.33348 \\
\hline 0.0175 & 10.60449 \\
\hline 0.02 & 9.991646 \\
\hline 0.0225 & 9.468969 \\
\hline 0.025 & 9.017448 \\
\hline 0.0275 & 8.622961 \\
\hline 0.03 & 8.274846 \\
\hline 0.0325 & 7.964935 \\
\hline 0.035 & 7.686876 \\
\hline 0.0375 & 7.435664 \\
\hline 0.04 & 7.207309 \\
\hline 0.0425 & 6.998585 \\
\hline 0.045 & 6.806863 \\
\hline 0.0475 & 6.629974 \\
\hline 0.05 & 6.466115 \\
\hline
\end{tabular}

Table 4:.Numerical solutions of Mass Transfer

\begin{tabular}{|c|c|c|}
\hline S.No & $\mathrm{S}_{\mathrm{c}}$ & $\mathrm{S}_{\mathrm{h}}$ \\
\hline 1 & 0.22 & 0.74986 \\
\hline 2 & 0.60 & 0.59846 \\
\hline 3 & 0.78 & 0.77986 \\
\hline
\end{tabular}

Table 5: Comparison of concentration profiles for water vapor $\mathrm{S}_{\mathrm{c}}=0.60, \mathrm{t}=0.0025$

\begin{tabular}{|r|r|r|}
\hline \multicolumn{1}{|c|}{$y$} & $\begin{array}{c}\text { Analytical } \\
\text { Solution }\end{array}$ & $\begin{array}{c}\text { Numerical } \\
\text { Solution }\end{array}$ \\
\hline 0 & 1 & 1 \\
\hline 0.05 & 1.14693 & 1.14682 \\
\hline 0.1 & 0.307983 & 0.30729 \\
\hline 0.15 & 0.08635 & 0.0823382 \\
\hline 0.2 & 0.022062 & 0.0220624 \\
\hline 0.25 & 0.005986 & 0.00591161 \\
\hline 0.3 & 0.001258 & 0.00158401 \\
\hline 0.35 & 0.0001148 & 0.00011372 \\
\hline 0.4 & 0.000985 & 0.00003044 \\
\hline 0.45 & 0.000456 & $8.06984 \mathrm{E}-6$ \\
\hline 0.5 & 0.000369 & $1.83187 \mathrm{E}-6$ \\
\hline 0.55 & 0.000892 & $7.4 \mathrm{E}-7$ \\
\hline 0.6 & 0.000098 & $4.8 \mathrm{E}-6$ \\
\hline 0.65 & 0.000069 & $0.6 \mathrm{E}-4$ \\
\hline 0.7 & 0.000086 & $0.2 \mathrm{E}-3$ \\
\hline 0.75 & 0.0000045 & $0.1 \mathrm{E}-4$ \\
\hline 0.8 & 0.0000001 & $0.1 \mathrm{E}-07$ \\
\hline 0.85 & $0.1 \mathrm{E}-05$ & $0.1 \mathrm{E}-08$ \\
\hline 0.9 & $0.1 \mathrm{E}-06$ & $0.1 \mathrm{E}-09$ \\
\hline 0.95 & $0.1 \mathrm{E}-06$ & $0.1 \mathrm{E}-11$ \\
\hline 1 & 0 & 0 \\
\hline
\end{tabular}

From the technological point of view, it is important to know the rate of heat transfer between the plate and the fluid. This can be found by using the non-dimensional quantity, the Nusselt number, $\mathrm{N}_{\mathrm{u}}$. The Nusselt number is defined as -ve gradient of the temperature. The numerical values of the Nusselt number against time $t$ are shown in Table 3. As $t$ increases, the rate of heat transfer at the plate decreases gradually. Finally for mass transfer we need the -ve gradient of concentration. This is denoted and defined as Schmidt number $\mathrm{S}_{\mathrm{c}}$. The numerical values of rate of mass transfer $S_{h}$ in terms of Sherwood number are obtained and have been shown in Table 4. From this table it can be observed that rate of mass transfer first increases gradually and then decreases as per gradual increase of the Schmidt number.

\section{Conclusions}

The heat and mass transfer in an unsteady MHD free convective flow past an infinite vertical plate with constant suction is studied numerically. From the above study, following conclusions can be drawn:

i) The transient temperature decreases for the increase of $y$.

ii) The transient concentration profiles decreases for the increase of $y$.

iii) The transient velocity profiles decreases for the increase of $y$.

iv) The rate of heat transfer at the plate decreases gradually.

v) The rate of mass transfer first increases gradually and then decreases. 


\section{References}

Carnahan, P., Luther, H.A. and Wilkes, J. O. (1969): Applied Numerical Methods, John Wiley \& Sons, USA.

Helmy, K.A., (1998): MHD Unsteady Free Convection Flow Past a Vertical Porous Plate, ZAMM Vol 78(4), pp. 225-270. doi:10.1002/(SICI)1521-4001(199804)78:4<255::AID-ZAMM255>3.0.CO;2-V

Acharya, M., Dash, G.C. and Singh, L. P. (2000): Magnetic Field Effects on the Free Convection and Mass Transfer Flow Through Porous Medium with Constant Suction and Constant Heat Flux, Indian J. Pure Appl. Math. 31(1), pp.1-18.

Young, J. K. (2000): Unsteady MHD Convective Heat Transfer Past A Semi-Infinite Vertical Porous Moving Plate with Variable Suction, Int. J. Engg. Sci, Vol 38, pp. 833-845. doi:10.1016/S0020-7225(99)00063-4

Chamkha, A. J. (2004): Unsteady MHD Convective Heat and Mass Transfer Past A Semi-Infinite Vertical Permeable Moving Plate with Heat Absorption, Int. J. Engg. Sci, Vol 42, pp. 217-230. doi:10.1016/S00207225(03)00285-4

Singh, A. K., Singh, A. K. and Singh, N. P. (2003), Heat And Mass Transfer In MHD Flow of a Viscous Fluid Past a Vertical Plate Under Oscillatory Suction Velocity, Indian. J. Pure Appl. Math., 34(3), pp. 429-442.

Sahoo, P.K., Datta, N. and Biswal, S. (2003): Magnetohydrodynamic Unsteady Free Convection Flow Past an Infinite Vertical Plate With Constant Suction and Heat Sink, Indian J. Pure Appl. Math., 34(1),pp .145-155.

Muthucumaraswamy, R. and Kumar, G. S. (2004): Heat and Mass Transfer Effects on Moving Vertical Plate in The Presence of Thermal Radiation, Theoret. Appl. Mech., Vol 31, No.1, pp. 35-46.

doi:10.2298/TAM0401035M 